\title{
INCLUDING CONTAINERS WITH DANGEROUS GOODS IN THE MULTI-PORT MASTER BAY PLANNING PROBLEM
}

\author{
Kiros Gebrearegawi Kebedow ${ }^{1}$, Johan Oppen ${ }^{2, *}$ \\ ${ }^{1}$ Hawassa University \\ School of Mathematical and Statistical Sciences \\ Hawassa, Ethiopia \\ kirosmaths@gmail.com \\ ${ }^{2}$ Molde University College, Specialized University in Logistics \\ Molde, Norway \\ Johan.Oppen@hiMolde.no
}

\begin{abstract}
In this paper we extend existing models for Master Bay Planning by handling containers holding dangerous goods, so-called IMO containers. Incompatible IMO containers must be separated from each other on board a vessel according to specific rules. These rules affect both Master Bay Planning and Slot Planning, which are the two planning problems normally handled in container stowage planning. Some research is done to include IMO containers in Slot Planning, but, to the best of our knowledge, this is the first time handling of IMO containers is included in Master Bay Planning. We present results from computational tests showing that our model can be solved to optimality, or near optimality, in reasonable time for realistically sized instances.
\end{abstract}

Keywords: Integer programming, Container stowage, Master Bay Planning, Dangerous goods

\section{Introduction and Literature Review}

The world economy is heavily dependent on the ability of transporting goods. Today, maritime transportation is the most important and cheapest mode of transportation in international trade. The introduction of containers represented a milestone in maritime transportation, which not only decreased transportation costs, but also helped to transport the goods safely. As a result, container transportation has become a predominant mode of cargo traffic. The majority of containers are transported by vessels called container ships, which are specifically designed to carry containers. According to [18] and 7], maritime transportation can be divided into three categories: industrial, tramp and liner shipping. In industrial shipping, the company owns both the cargoes transported and the ships transporting them, and the aim is to minimize the cost of the voyages. Tramp vessels follow the available cargoes and can be thought of as taxis. A tramp shipping company may have a certain amount of contract cargoes which it is committed to carry, and tries to maximize the profit from optional spot cargoes. In liner shipping, ships follow fixed routes with a public schedule and aim to maximize profit on the given routes. Container ships usually operate within the liner shipping segment, and they are owned by different shipping companies. One of the main goals for liner shipping companies, in order to maximize profit, is to load and unload their ships fast. This does not only reduce port fees, but also allows for decreasing the speed at sea, which save fuel consumption and $\mathrm{CO}_{2}$ emissions [11.

Because of its combinatorial nature and the various operating constraints related to both the ship structure and container properties, stowage planning is a complex problem. Publications on container stowage planning can be divided into two main categories: single phase and multi-phase approaches. Single phase approaches represent the stowage planning problem in a single optimization model, whereas multi-phase approaches decompose the problem into two or more phases. The most successful approaches found in recent literature, see, e.g., [1, 12, 9, 16, 14], decompose the problem into two phases: the Master Bay Planning Problem (MBPP) and the Slot Planning Problem (SPP). The Master Bay Planning Problem distributes the containers to bay sections of the vessel, the Slot Planning Problem then assigns the containers in each bay section to specific slots. We also choose a two-phase approach, and in this paper we develop a new model for the Multi-Port Master Bay Planning Problem (MP-MBPP). We believe the added features of this model give a more realistic description of container stowage planning.

Ambrosino et al. [4 introduce two mixed integer programming models for the MP-MBPP, dealing with practical and operational aspects of the problem: minimizing unmet demand, crane imbalance, and number of re-handles. Only standard containers of length $20^{\prime}$ and $40^{\prime}$ are modeled, and two different heuristic approaches are proposed to solve the problem. Ambrosino et al. 5] presents a new mixed integer programming model 
for the MP-MBPP that takes into account standard, reefer and open top containers of lengths $20^{\prime}$ and $40^{\prime}$, and hatch cover positions in the ships. The objective is to minimize the number of re-handles and imbalanced crane work. In the models presented in [2, 3, 4, 5, 10, the constraints dealing with transversal and longitudinal stability are constructed by forcing the weight on the right side of the ship to be equal to the weight on the left side of the ship within given tolerances, and the weight on the stern of the ship to be equal to the weight on the bow of the ship within given tolerances. In addition, the constraints dealing with vertical stability and metacentric height are constructed by forcing containers to be stowed in ascending order of weight from the bottom to the top in the same stack.

Pacino et al. 11] also decompose the stowage planning problem into the Multi-Port Master Bay Planning Problem and the Slot Planning Problem. In the MP-MBPP, an integer programming model that assigns groups of different container types (standard light, standard heavy, reefer light and reefer heavy) to locations of the container ship is presented. This model is then solved after relaxing some of the variables. Pacino et al. [12. develop a linear integer programming model with ballast tanks which leads to variable displacement for the MP-MBPP. They present a linearization approach for the center of gravity and hydrostatic data tables of the vessel, to formulate stability and stress constraints that can handle variable displacement. The objective is to minimize the changes in ballast water.

Parreño et al. 13. develop a binary programming model and a GRASP algorithm to solve the Slot Planning Problem where handling of IMO containers is included. In 1, the authors develop a bin packing approach to handle the Master Bay Planning Problem, which is different from our way of modeling and solving the problem. These are the only two papers we have been able to find which deal with IMO containers. The Slot Planning Problem focuses on the second phase of container stowage planning, and thus [1] is the only research on Master Bay Planning dealing with IMO containers we have found.

The main contribution of our paper is that we include containers with dangerous goods, so-called IMO containers (IMO - the International Maritime Organization) in our model, and we show that, despite this extension, the model is solved to optimality or near optimality for realistically sized instances by standard software in reasonable time.

The remainder of the paper is organized as follows: in Section 2 we provide a description of our version of the Multi-Port Master Bay Planning Problem. Our mathematical model is presented in Section 3, while we present computational results in Section 4 . Finally, Section 5 concludes the paper.

\section{Problem Description}

A container is a metal box in which goods can be stored, and all containers are standardized according to the ISO 668 standard. The size of a container refers to its metrics of length, width, and height, which are usually expressed in feet $\left(^{\prime}\right)$ and inches $\left({ }^{\prime \prime}\right)$. The most commonly used container heights are $0^{\prime}, 8^{\prime} 6^{\prime \prime}$, and $9^{\prime} 6^{\prime \prime}$, and most commonly used lengths are $20^{\prime}, 40^{\prime}$, and $45^{\prime}$. A $20^{\prime}$ container is referred to as a Twenty foot Equivalent Unit (TEU), a 40' container is called a Forty foot Equivalent Unit (FEU). All standard ISO containers are $8^{\prime}$ wide. A $0^{\prime}$ height container is called a platform whereas a $9^{\prime} 6^{\prime \prime}$ container is called a high-cube container. Reefer containers are containers which allow contents to be kept cool, and must be supplied with electricity. Containers carrying dangerous goods are referred to as IMO containers, see Section 2.1.

A container ship or container vessel is a cargo ship designed to hold containerized cargo. The vessel's cargo space is divided into bays, each bay is partitioned into on-deck and below deck parts using a hatch cover, which is a metallic, flat, water proof lid which allows containers to be stored on top of it. The below deck part of the ship is physically divided into several cargo holds by upright walls within the hull of the ship called bulkheads, which are indicated by the bold vertical lines in Figure 1. Today, the largest container ships in the world are able to carry more than 20000 TEUs [15].

Both the on-deck and below deck parts of the vessel are partitioned into cells which contain two TEUs or one FEU container each. The cells are divided into two slots, a fore and an aft slot.

A slot is described by three parameters called the bay, row, and tier. A bay is a longitudinal section of a vessel. Bays are numbered from the bow to the stern of the vessel. TEU bays are numbered with odd numbers $(01,03,05,07, \ldots)$ whereas FEU bays are numbered with even numbers $(02,06,10, \ldots)$. The numbering of FEU bays depend on the particular structure of the container ship, but in any case, each FEU bay is associated with two contiguous TEU bays, e.g bay $06=$ bay $05+$ bay 07 , as depicted in Figure 1. A row or stack is a transversal section of a vessel. Rows are numbered from centerline to port side with even numbers and from centerline to starboard with odd numbers. The row on the centerline is numbered 00, as shown in Figure 2 A tier is the vertical view of the cells of a vessel. Below deck tiers are numbered vertically upwards with even numbers from bottom to top, starting from 02 . On-deck tiers are numbered vertically upwards with even numbers starting from 82 . Thus, the tiers on-deck can be numbered by the sequence $82,84,86, \cdots$, as depicted in Figure 2 .

Most cells can hold one $40^{\prime}$ or $45^{\prime}$ container, or two $20^{\prime}$ containers. $45^{\prime}$ containers can only be loaded in cells meant for such containers or on the upper tier (on-deck) of an FEU bay, and some cells may be restricted to 


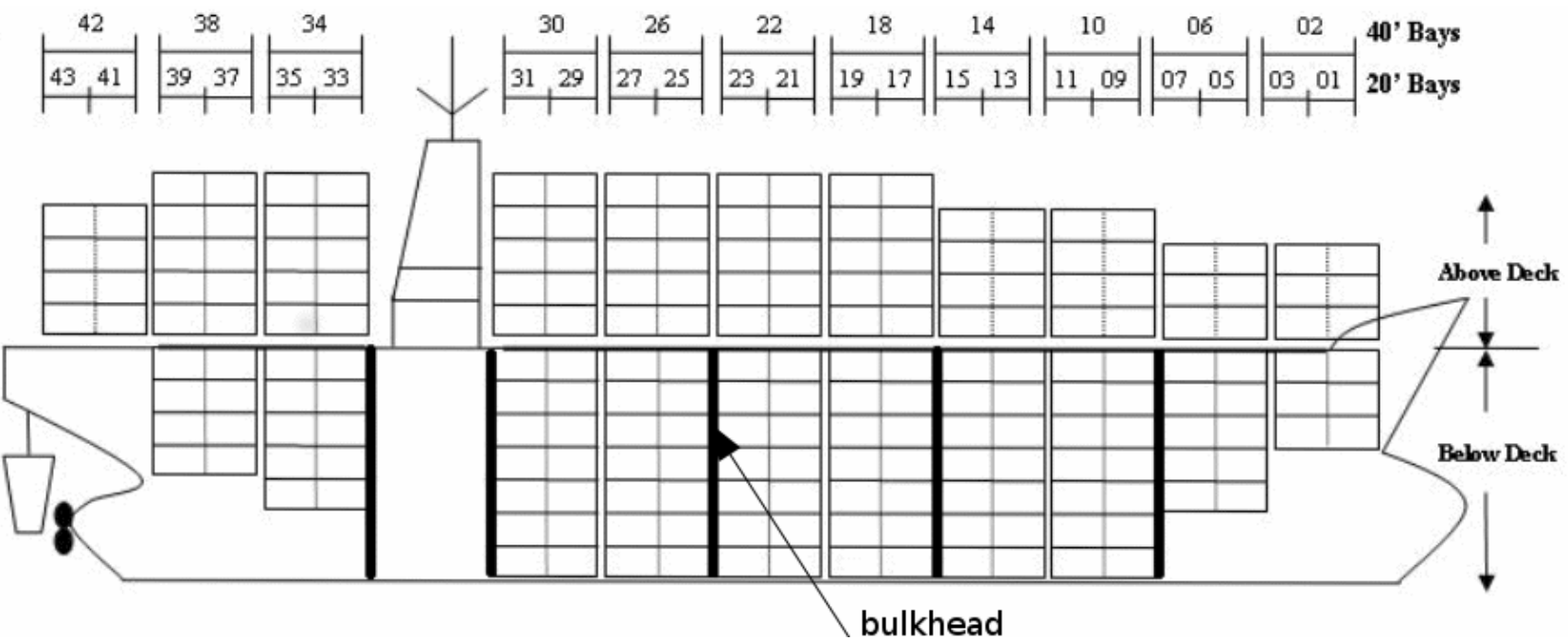

Figure 1: The longitudinal view of a container ship. The numbering of TEU and FEU bays are shown at the top $[8$.

either $20^{\prime}$ or $40^{\prime}$ containers. Due to the physical layout of the vessel, there exist odd cells that hold only one $20^{\prime}$ container. Loaded containers are containers which are already on board a vessel when the stowage plan is made. The list of containers to load in the current port is called the load list. It contains detailed information about the containers, such as height, length, weight, type (standard, reefer, IMO) and discharge port. The stowing rules for IMO containers are explained in Section 2.1. A release is a list of loaded containers, which has the container information from the load list plus the exact position where each container is stowed.

Containers stowed in a row form a stack which is one container wide, and is composed of two TEU bays and a single FEU bay. A location is a bay section which consists of a set of stacks that are either on or below deck, the stacks are adjacent and they coincide with the same hatch cover for bays with three hatch covers, as depicted in Figure 3a, or they coincide with two or three adjacent hatch covers for bays with seven hatch covers, as depicted in Figure 3b Any location has a maximum TEU capacity, a maximum reefer container capacity, maximum capacities for different types of IMO containers, and weight limits.

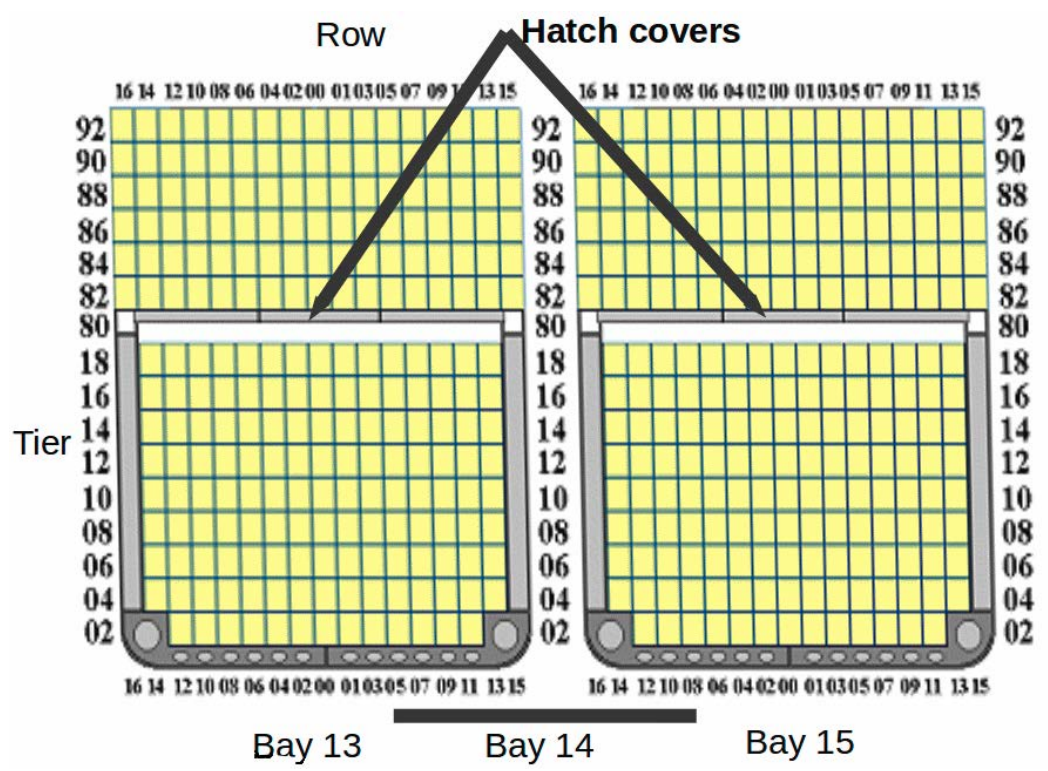

Figure 2: Transversal view of an even bay. The numbering of rows and tiers are shown horizontally and vertically, respectively.

Containers on a container ship are stowed in vertical stacks. A common situation is that, at port $A$, a container with port of destination (POD) $B$ must be unloaded and reloaded at port $A$ in order to access the container below it, which has port $A$ as POD. This stowage configuration is called over-stowage, and costs both time and money for shipping line companies. Two types of over-stowage are normally considered: when a container is unloaded, the containers above it in the same stack must be unloaded first. This situation is 


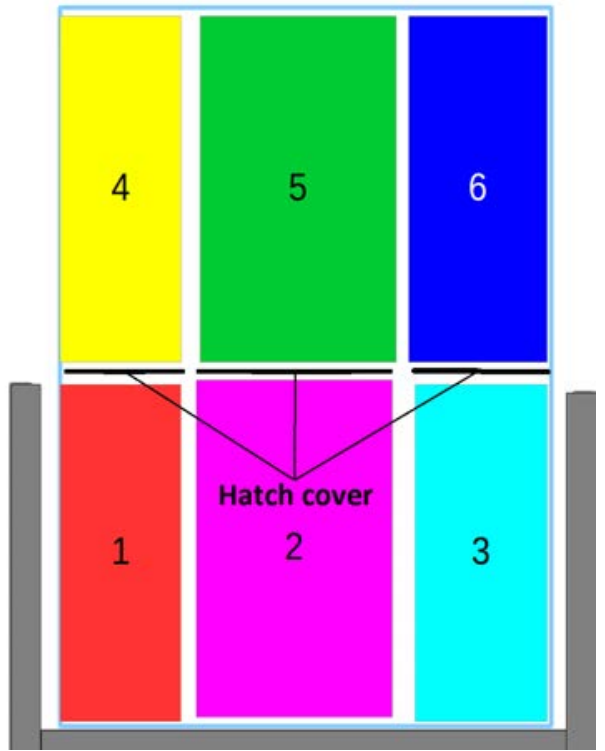

(a)

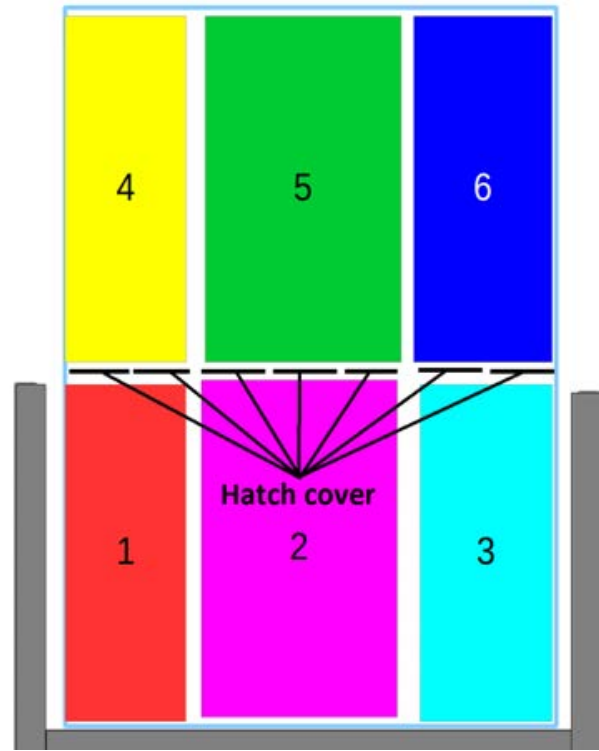

(b)

Figure 3: Locations in a bay with three (a) and seven hatch covers (b).

referred to as over-stowage within location. If the container is stowed below a hatch, all containers above this hatch must also be unloaded in order to open the hatch. This is called hatch over-stowage.

When a container ship is ready to leave a port it must be declared seaworthy, which means that all loaded items, i.e., cargo, ballast water, fuel, etc., must be distributed along the vessel such that its initial stability is acceptable, all stress forces are within limits and the draft, trim and metacentric height of the ship are also within limits. We direct interested readers to [11 and 12 for a more detailed description of how vessel stability is computed and modeled. The constraints related to stability in this paper are similar to those in [11.

\subsection{IMO Classes and Stowage Rules}

According to the International Maritime Dangerous Goods Code (IMDG Code), there are nine classes of dangerous goods, some of these are divided into subclasses, currently making up a total of 17 classes. Detailed information can be found in [1]. Due to their properties, many of these substances are incompatible to each other, and thus a minimum distance has to be kept between them. For this purpose, the IMDG Code provides a number of separation rules as indicated in Table1.

As shown in Table 1. there exist four specific separation principles that must be followed for the stowage of dangerous goods, each of them giving detailed rules for how to separate pairs of containers holding incompatible goods: (1) Away from, (2) Separated from, (3) Separated by a complete compartment from, and (4) Separated longitudinally by an intervening complete compartment or hold from. Principle (1) only affects the stowing of open top containers which are not included in this paper, thus only principles $2-4$ are considered here. The cells marked ' $\mathrm{X}$ ' in Table 1 refer to combinations of goods where the concrete substances will lead to a certain principle $(1,2,3$ or 4$)$ to be applied.

\section{Principle 2: Separated from}

This principle means the containers cannot be placed in the same stack (row), unless separated by a deck, while they can be stowed horizontally (in both longitudinal and transversal directions) separated by one container space. If there is a bulkhead between them, one container space is not necessary. For instance, given two incompatible IMO containers stowed according to principle 2, if one container is stowed in bay 15 , row 09 , tier 10 , the other can be stowed in bay 17 , row 09 , tier 10 (bacause there is a bulkhead between bays 14 and 18), as illustrated in Figure 4.

\section{Principle 3: Separated by a complete compartment from}

This principle means that two containers on deck cannot be placed in the same stack, while they can be stowed longitudinally separated by one container space and transversally separated by two container spaces. For example, given two incompatible IMO containers stowed according to principle 3 , if one container is stowed in bay 19, row 03 , tier 88, the other cannot be stowed in on-deck locations of rows $02,01,03,05$, or 07 of bays 17 , 19 or 21 as illustrated in Figure 4. Below deck, two containers stowed according to principle 3 cannot be placed in the same stack, horizontally they must be separated by a bulkhead. For instance, given two incompatible 
Table 1: Separation table, adopted from [1].

\begin{tabular}{|c|c|c|c|c|c|c|c|c|c|c|c|c|c|c|c|c|c|c|}
\hline IMO Class & & $\begin{array}{l}1.1 \\
1.2 \\
1.5\end{array}$ & $\begin{array}{l}1.3 \\
1.6\end{array}$ & 1.4 & 2.1 & 2.2 & 2.3 & 3.0 & 4.1 & 4.2 & 4.3 & 5.1 & 5.2 & 6.1 & 6.2 & 7.0 & 8.0 & 9.0 \\
\hline Explosives & $\begin{array}{c}1.1 \\
1.21 .5\end{array}$ & $\mathrm{x}$ & $\mathrm{x}$ & $\mathrm{x}$ & 4 & 2 & 2 & 4 & 4 & 4 & 4 & 4 & 4 & 2 & 4 & 2 & 4 & $\mathrm{x}$ \\
\hline Explosives & 1.31 .6 & $\mathrm{x}$ & $\mathrm{x}$ & $\mathrm{x}$ & 4 & 2 & 2 & 4 & 3 & 3 & 4 & 4 & 4 & 2 & 4 & 2 & 2 & $\mathrm{x}$ \\
\hline Explosives & 1.4 & $\mathrm{x}$ & $\mathrm{x}$ & $\mathrm{x}$ & 2 & 1 & 1 & 2 & 2 & 2 & 2 & 2 & 2 & $\mathrm{x}$ & 4 & 2 & 2 & $\mathrm{x}$ \\
\hline Flammable gases & 2.1 & 4 & 4 & 2 & $\mathrm{x}$ & $\mathrm{x}$ & $\mathrm{x}$ & 2 & 1 & 2 & $\mathrm{x}$ & 2 & 2 & $\mathrm{x}$ & 4 & 2 & 1 & $\mathrm{x}$ \\
\hline $\begin{array}{c}\text { Non-toxic, } \\
\text { non-flammable gases } \\
\end{array}$ & 2.2 & 2 & 2 & 1 & $\mathrm{x}$ & $\mathrm{x}$ & $\mathrm{x}$ & 1 & $\mathrm{x}$ & 1 & $\mathrm{x}$ & $\mathrm{x}$ & 1 & $\mathrm{x}$ & 2 & 1 & $\mathrm{x}$ & $\mathrm{x}$ \\
\hline Toxic gases & 2.3 & 2 & 2 & 1 & $\mathrm{x}$ & $\mathrm{x}$ & $\mathrm{x}$ & 2 & $\mathrm{x}$ & 2 & $\mathrm{x}$ & $\mathrm{x}$ & 2 & $\mathrm{x}$ & 2 & 1 & $\mathrm{x}$ & $\mathrm{x}$ \\
\hline Flammable liquid & 3 & 4 & 4 & 2 & 2 & 1 & 2 & $\mathrm{x}$ & $\mathrm{x}$ & 2 & 1 & 2 & 2 & $\mathrm{x}$ & 3 & 2 & $\mathrm{x}$ & $\mathrm{x}$ \\
\hline Flammable solids & 4.1 & 4 & 3 & 2 & 1 & $\mathrm{x}$ & $\mathrm{x}$ & $\mathrm{x}$ & $\mathrm{x}$ & 1 & $\mathrm{x}$ & 1 & 2 & $\mathrm{x}$ & 3 & 2 & 1 & $\mathrm{x}$ \\
\hline $\begin{array}{c}\text { Substances liable to } \\
\text { spontaneous combustion }\end{array}$ & 4.2 & 4 & 3 & 2 & 2 & 1 & 2 & 2 & 1 & $\mathrm{x}$ & 1 & 2 & 2 & 1 & 3 & 2 & 1 & $\mathrm{x}$ \\
\hline $\begin{array}{l}\text { Substances which, } \\
\text { in contact with water } \\
\text { emit flammable gases }\end{array}$ & 4.3 & 4 & 4 & 2 & $\mathrm{x}$ & $\mathrm{x}$ & $\mathrm{x}$ & 1 & $\mathrm{x}$ & 1 & $\mathrm{x}$ & 2 & 2 & $\mathrm{x}$ & 2 & 2 & 1 & $\mathrm{x}$ \\
\hline $\begin{array}{c}\text { Oxidizing substances } \\
\text { (agents) }\end{array}$ & 5.1 & 4 & 4 & 2 & 2 & $\mathrm{x}$ & $\mathrm{x}$ & 2 & 1 & 2 & 2 & $\mathrm{x}$ & 2 & 1 & 3 & 1 & 2 & $\mathrm{x}$ \\
\hline Organic peroxide & 5.2 & 4 & 4 & 2 & 2 & 1 & 2 & 2 & 2 & 2 & 2 & 2 & $\mathrm{x}$ & 1 & 3 & 2 & 2 & $\mathrm{x}$ \\
\hline Toxic substance & 6.1 & 2 & 2 & $\mathrm{x}$ & $\mathrm{x}$ & $\mathrm{x}$ & $\mathrm{x}$ & $\mathrm{x}$ & $\mathrm{x}$ & 1 & $\mathrm{x}$ & 1 & 1 & $\mathrm{x}$ & 1 & $\mathrm{x}$ & $\mathrm{x}$ & $\mathrm{x}$ \\
\hline Infectious substance & 6.2 & 4 & 4 & 4 & 4 & 2 & 2 & 3 & 3 & 3 & 2 & 3 & 3 & 1 & $\mathrm{x}$ & 3 & 3 & $\mathrm{x}$ \\
\hline Radioactive material & 7.0 & 2 & 2 & 2 & 2 & 1 & 1 & 2 & 2 & 2 & 2 & 1 & 2 & $\mathrm{x}$ & 3 & $\mathrm{x}$ & 2 & $\mathrm{x}$ \\
\hline Corrosive substance & 8.0 & 4 & 2 & 2 & 1 & $\mathrm{x}$ & $\mathrm{x}$ & $\mathrm{x}$ & 1 & 1 & 1 & 2 & 2 & $\mathrm{x}$ & 3 & 2 & $\mathrm{x}$ & $\mathrm{x}$ \\
\hline $\begin{array}{c}\text { Miscellaneous } \\
\text { dangerous substances } \\
\text { and article }\end{array}$ & 9.0 & $\mathrm{x}$ & $\mathrm{x}$ & $\mathrm{x}$ & $\mathrm{x}$ & $\mathrm{x}$ & $\mathrm{x}$ & $\mathrm{x}$ & $\mathrm{x}$ & $\mathrm{x}$ & $\mathrm{x}$ & $\mathrm{x}$ & $\mathrm{x}$ & $\mathrm{x}$ & $\mathrm{x}$ & $\mathrm{x}$ & $\mathrm{x}$ & $\mathrm{x}$ \\
\hline
\end{tabular}

IMO containers stowed according to principle 3, if one container is put below deck in any row of bay 19 , then the other cannot be put in any below deck locations belonging to bays 17, 19, 21 or 23 as illustrated in Figure 4. Note that there is a bulkhead between bay 14 and bay 18 .

Principle 4: Separated longitudinally by an intervening complete compartment or hold from This principle means in on-deck locations, two containers cannot be placed in the same stack, longitudinally they require a minimum of $24 \mathrm{~m}$ (four $20^{\prime}$ containers spaces ${ }^{1}$ ) separation, including a complete bay. Incompatible IMO containers stowed according to principle 4 stowed in below deck locations in addition require a bulkhead separation. For example, given two incompatible IMO containers stowed according to principle 4, if one container is stowed in any location in bay 19, the other cannot be stowed in any location (both on-deck and below deck) of bay $13,15,17,21,23$, or 25 . The separation principles described above are summarized in Table 2, which is taken from [19].

Table 2: Separation principles.

\begin{tabular}{|c|c|c|c|c|}
\hline \multirow[b]{2}{*}{ Principle } & \multirow[b]{2}{*}{ Vertical } & \multicolumn{3}{|c|}{ Horizontal } \\
\hline & & & On-deck & Below deck \\
\hline \multirow[b]{2}{*}{1} & \multirow{2}{*}{$\begin{array}{c}\text { One on top } \\
\text { of another allowed }\end{array}$} & Fore and aft & No restriction & No restriction \\
\hline & & Athwartship & No restriction & No restriction \\
\hline \multirow[t]{2}{*}{2} & \multirow{2}{*}{$\begin{array}{c}\text { Not in the same } \\
\text { vertical line unless } \\
\text { separated by deck }\end{array}$} & Fore and aft & One container space & $\begin{array}{c}\text { One container space } \\
\text { or bulkhead }\end{array}$ \\
\hline & & Athwartship & One container space & One container space \\
\hline \multirow[t]{2}{*}{3} & \multirow{2}{*}{$\begin{array}{c}\text { Not in the same } \\
\text { vertical line unless } \\
\text { separated by deck }\end{array}$} & Fore and aft & One container space & One bulkhead \\
\hline & & Athwartship & Two container spaces & One bulkhead \\
\hline \multirow[t]{2}{*}{4} & \multirow[t]{2}{*}{ Not allowed } & Fore and aft & $\begin{array}{l}\text { Minimum horizontal } \\
\text { distance of } 24 \mathrm{~m}\end{array}$ & $\begin{array}{l}\text { One bulkhead and } \\
\text { minimum horizontal } \\
\text { distance of } 24 \mathrm{~m} \text {, } \\
\text { at least } 6 \mathrm{~m} \\
\text { from bulkhead }\end{array}$ \\
\hline & & Athwartship & Not allowed & Not allowed \\
\hline
\end{tabular}

A stowage plan is a document describing where each container should be placed in the vessel after terminal operations start. Stowage planning naturally decomposes into two phases, Master Bay Planning and Slot Planning. Optimization models developed for Master Bay Planning contain high level constraints, mainly regarding the stability of the vessel, whereas optimization models for Slot Planning contain low level constraints

\footnotetext{
${ }^{1}$ The open space between two consecutive even bays is $3 \mathrm{~m}$.
} 


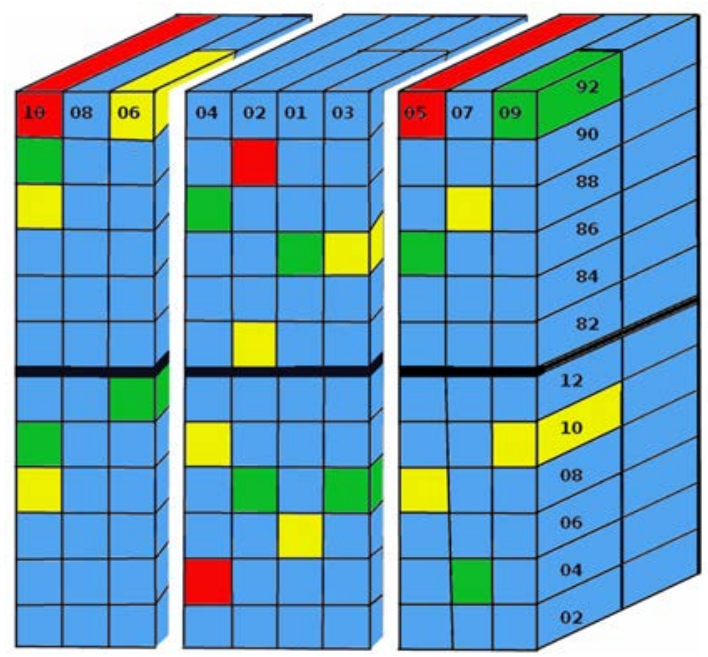

(a) Bay 14 (15 in the front, 13 in the back)

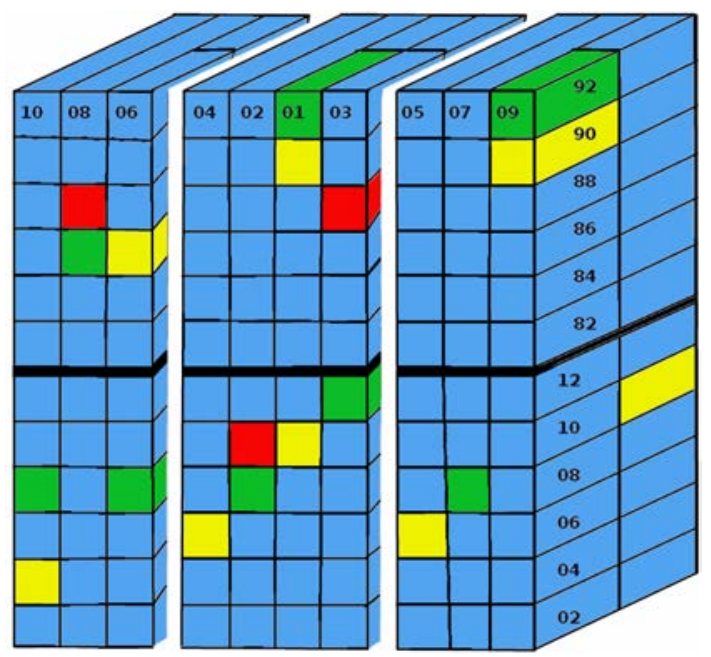

(b) Bay 18 (19 in the front, 17 in the back)

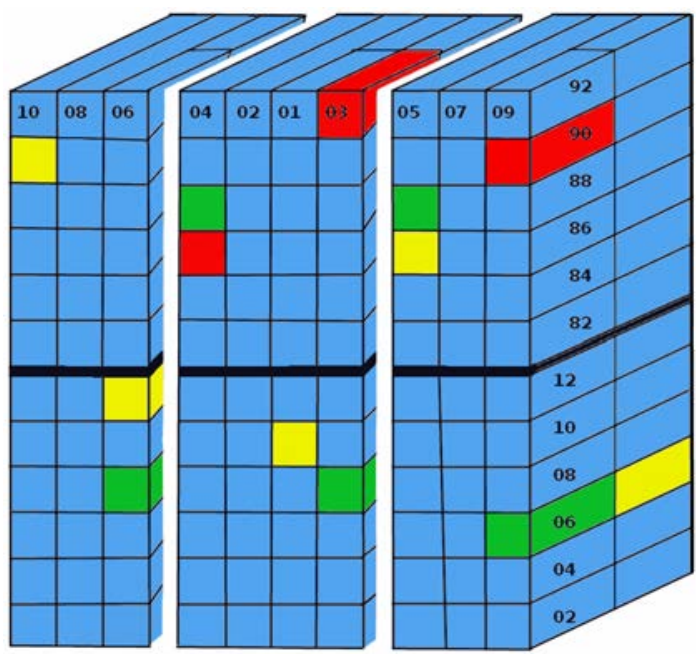

(c) Bay 22 (23 in the front, 21 in the back)

Figure 4: A container stowage configuration of two different incompatible groups of IMO containers following principle 2 (one group in yellow and the other group in green) and one incompatible group of IMO containers following principle 3 (in red) in three adjacent even bays. The setup is based on Figure 1, thus there is a bulkhead between bays 14 and 18 .

mainly concerning the stacking rules. Since incompatible containers following principle 3 stowed below deck and all incompatible containers following principle 4 need a complete bay separation, they are only considered in Master Bay Planning. However, all incompatible containers following principle 2 and incompatible containers following principle 3 stowed on-deck are considered in both Master Bay Planning and Slot Planning.

In this paper, we focus on the Multi-Port Master Bay Planning Problem (MP-MBPP). Our model is based on the integer programming model presented by Pacino et al.11, where the authors consider standard and reefer containers of $20^{\prime}$ and $40^{\prime}$ length with two weight classes for each length. Each bay, assuming three (or seven) hatch covers in each bay, is divided into four locations, two on-deck and two below deck. An inner location is the middle stacks of a bay coinciding with the middle (one or three) hatch cover(s), whereas an outer location contains both the water side and port side stacks of the same bay, coinciding with the two (or four) remaining hatch covers. This means that outer locations are symmetrically split to ensure transversal stability. Using Figure 3 as an example, locations 2 and 5 would be the two inner locations, locations 1 and 3 would be in the same outer location, the second outer location would contain the two on-deck locations 4 and 6 . Pacino et al.[11] also assume constant displacement of the ship along the trip, and the current and downstream ports are considered.

Our version of the Multi-Port Master Bay Planning Problem extends this model by including IMO containers as outlined above, and by splitting the outer locations from 11 into two locations each, one for each side of the vessel. This definition of locations helps us to handle hatch over-stowage in a more realistic way, as there is 
no need to remove containers from more than one hatch cover to get access to a given below deck container for container-ships with three hatch covers in each bay and there is no need to remove containers from more than three hatch covers to get access to a given below deck container for container ships with seven hatch covers in each bay. We model the transversal stability requirements for the vessel as constraints. Since a location consists of a set of stacks, over-stowage within a location is not handled in the Master Bay Planning phase, but rather in the Slot Planning phase. This also reduces the time needed to solve the model. A feasible solution for the MP-MBPP must then satisfy the following rules.

- R1: For each location and each port, the number of containers of length $20^{\prime}$ and $40^{\prime}$ must be within TEU and FEU capacity limits of the location, respectively.

- R2: For each location and each port, the number of reefer containers must be within the reefer capacity limit of the location.

- R3: For each port, the number of incompatible IMO containers must be within the location capacity so that the separation principles given in Table 2 are respected.

- R4: All containers in the load list of the current and downstream ports must be loaded.

- R5: For each location and each port, the total weight of containers must be within the weight limits of the location.

- R6: For each port, the transversal, longitudinal and vertical center of gravity must be within the limits when loading is completed.

- R7: For each port, the stress forces of each frame must be within the limits when loading is completed.

The objective function of the MP-MBPP is to minimize the costs of hatch over-stowage, the makespan of the cranes along the trip, and the number of non reefer containers stowed in reefer slots.

\section{A Mathematical Model for the Multi-Port Master Bay Planning Problem}

The MP-MBPP distributes types of containers to load in the port into bay subsections called locations. We now introduce our integer programming model formulated to solve the MP-MBPP.

\subsection{Notation}

In this subsection, we present the notation used in the model. Sets are listed in Table 3 , constants are given in Table 4, and variables are listed in Table 5.

Containers are divided into types according to properties of the container itself (standard/reefer), the goods stored in the container (IMO classes) and the weight of the container including its content (heavy/light). As shown in Table 1, there are currently 17 classes of dangerous goods. We consider the containers containing one class of dangerous goods as one IMO container type. The IMO containers of each class are incompatible with other IMO containers by respecting one of the separation principles, so the incompatible containers must be stored according to the stowing rules for the given principle. The fact that all containers types may include both $20^{\prime}$ and 40' containers are handled by separating the input data and the $x$ variables by container length.

We include only even bays in the set $\mathcal{B}$, as there is no need to keep track of the fore and aft parts of each bay in the master planning.

Locations are also grouped based on different properties, the rules for separating IMO containers make it necessary to keep track of below deck and on-deck locations, and locations in adjacent bays.

A transport is a pair of load-discharge ports $\left(p_{i}, p_{j}\right)$ where containers can be transported from port $\left(p_{i}\right)$ to port $\left(p_{j}\right)$, that is, port $\left(p_{i}\right)$ is visited before port $\left(p_{j}\right)$.

The two forces: gravity force acting downwards and buoyancy force acting upward, are not uniformly distributed along the containership. Although a containership is not divided into independent sections, the two forces create stress forces in the structure of the containership. Limits on these stress forces are given for a set of points along the containership called frames.

The $x^{\alpha}$ variables are the decision variables of the problem, assigning the number of $20^{\prime}$ and $40^{\prime}$ containers of each type to be stowed in each location of the container ship during each transport. The binary variables $\delta$ indicate hatch over-stowage. The variables $y^{O}$ calculate the amount of hatch over-stowage. The variables $y^{T}$ and $y^{R}$ calculate crane makespan and reduced reefer container capacity, respectively. 
Table 3: Sets

\begin{tabular}{|c|c|}
\hline $\mathcal{D}$ & Classes of dangerous goods. \\
\hline $\mathcal{S}$ & Separation principles $\{2,3,4\}$. \\
\hline $\mathcal{T}$ & $\begin{array}{l}\text { Container types (Standard heavy, Standard light, Reefer heavy, Reefer light, } \\
\text { IMOC }_{1} \text { heavy, IMOC } \mathrm{IMC}_{1} \text { light, } \mathrm{IMOC}_{2} \text { heavy, } \ldots, \mathrm{IMOC}_{|\mathcal{D}|} \text { light). }\end{array}$ \\
\hline $\mathcal{T}_{R}$ & Reefer container types (Reefer heavy, Reefer light). \\
\hline $\mathcal{T}_{d}$ & Container types for dangerous goods of class $d$ (IMOC $d$ heavy, $\mathrm{IMOC}_{d}$ light). \\
\hline $\begin{array}{l}\mathcal{T}_{d}^{j} \\
\mathcal{H}\end{array}$ & $\begin{array}{l}\text { Container types following separation principle } j \text { with respect to containers of type } \mathcal{T}_{d} \text {. } \\
\text { Bulkheads. }\end{array}$ \\
\hline $\mathcal{H}^{\mathcal{A D} \mathcal{J}}$ & Pairs of adjacent bulkheads $\{(1,2),(2,3), \cdots,(|\mathcal{H}|-1,|\mathcal{H}|)\}$ \\
\hline $\mathcal{B}$ & Even bays $\{2,6,10, \cdots\}$. \\
\hline $\mathcal{B}^{E X}$ & Pairs of exclusive adjacent bays $\{(2,6),(10,14), \cdots\}$. \\
\hline $\mathcal{B}^{I N}$ & Pairs of inclusive adjacent bays $\{(2,6),(6,10), \cdots\}$. \\
\hline $\mathcal{L}$ & Locations. \\
\hline $\mathcal{L}^{O}$ & On-deck locations. \\
\hline $\mathcal{L}^{U}$ & Below deck locations. \\
\hline $\mathcal{L}_{l}^{U}$ & Below deck location below on-deck location $l$. \\
\hline $\mathcal{L}_{h h^{\prime}}^{U}$ & Below deck locations between two adjacent bulkheads $h$ and $h^{\prime}$. \\
\hline $\mathcal{L}_{b}^{n n}$ & Locations in pair $b$ of exclusive adjacent bays. \\
\hline$\widetilde{\mathcal{L}_{b}^{I}}$ & Locations in pair $b$ of inclusive adjacent bays. \\
\hline $\mathcal{P}$ & Ports to be visited by the vessel. \\
\hline $\mathcal{R}$ & Transports, represented by a load-discharge port pair $\left(p_{i}, p_{j}\right)$. \\
\hline $\mathcal{R}_{p}$ & Transports with containers on the vessel at departure from port $p$. \\
\hline $\mathcal{R}_{p}^{A}$ & Transports loaded or unloaded in port $p$ \\
\hline $\mathcal{R}_{p}^{O V}$ & Transports which over-stow containers to load or unload in port $p$. \\
\hline & Frames (sets of bays associated with vessel stability). \\
\hline $\mathcal{L}_{f}^{A F T}$ & Locations aft of frame $f$. \\
\hline
\end{tabular}

\subsection{Formulation}

The integer programming model is formulated as follows:

$$
\min \sum_{p \in \mathcal{P}} \sum_{l \in \mathcal{L}}\left(C^{O} y_{p l}^{O}+C^{R} y_{p l}^{R}\right)+\sum_{p \in \mathcal{P}} C^{T} y_{p}^{T}
$$

subject to

$$
\begin{gathered}
\sum_{r \in \mathcal{R}_{p}} \sum_{t \in \mathcal{T}}\left(x_{r l}^{20 t}+2 x_{r l}^{40 t}\right) \leq C_{p l}^{T}, \quad p \in \mathcal{P}, l \in \mathcal{L} \\
\sum_{r \in \mathcal{R}_{p}} \sum_{t \in \mathcal{T}_{R}}\left(x_{r l}^{20 t}+2 x_{r l}^{40 t}\right) \leq C_{p l}^{R}, \quad p \in \mathcal{P}, l \in \mathcal{L} \\
\sum_{r \in \mathcal{R}_{p}} \sum_{t \in \mathcal{T}_{d}} \sum_{\alpha \in\left\{20^{\prime}, 40^{\prime}\right\}} x_{r l}^{\alpha t} \leq \phi_{p l}^{d} M, \quad p \in \mathcal{P}, l \in \mathcal{L}, d \in \mathcal{D} \\
\sum_{r \in \mathcal{R}_{p}} \sum_{t \in \mathcal{T}_{d}} \sum_{\alpha \in\left\{20^{\prime}, 40^{\prime}\right\}} x_{r l}^{\alpha t} \geq \phi_{p l}^{d}, \quad p \in \mathcal{P}, l \in \mathcal{L}, d \in \mathcal{D} \\
\sum_{r \in \mathcal{R}_{p}} \sum_{t \in \mathcal{T}_{d}^{j}} \sum_{\alpha \in\left\{20^{\prime}, 40^{\prime}\right\}} x_{r l}^{\alpha t}-\left(1-\phi_{p l}^{d}\right) M \leq C_{p l}^{j d}, \quad p \in \mathcal{P}, l \in \mathcal{L}, d \in \mathcal{D}, j \in \mathcal{S} \backslash\{4\} . \\
\sum_{r \in \mathcal{R}_{p}} \sum_{l \in \mathcal{L}_{h h^{\prime}}^{U}} \sum_{t \in \mathcal{T}_{d}^{3}} \sum_{\alpha \in\left\{20^{\prime}, 40^{\prime}\right\}} x_{r l}^{\alpha t} \leq \lambda_{\left(h h^{\prime}\right) p}^{d} M_{3}, \quad p \in \mathcal{P}, d \in \mathcal{D},\left(h h^{\prime}\right) \in \mathcal{H}^{\mathcal{A D} \mathcal{J}} \\
\sum_{r \in \mathcal{R}_{p}} \sum_{l \in \mathcal{L}_{h h^{\prime}}^{U}} \sum_{t \in \mathcal{T}_{d}^{3}} \sum_{\alpha \in\left\{20^{\prime}, 40^{\prime}\right\}} x_{r l}^{\alpha t} \geq \lambda_{\left(h h^{\prime}\right) p}^{d}, \quad p \in \mathcal{P}, d \in \mathcal{D},\left(h h^{\prime}\right) \in \mathcal{H}^{\mathcal{A D} \mathcal{J}}
\end{gathered}
$$


Table 4: Constants

\begin{tabular}{|c|c|}
\hline$C_{n l}^{T}$ & TEU capacity of location $l$ in port $p$. \\
\hline$C_{p l}^{R l}$ & Reefer container capacity of location $l$ in port $p$. \\
\hline$C_{p l}^{\alpha u}$ & Capacity of $\alpha \in\left\{20^{\prime}, 40^{\prime}\right\}$ containers in location $l$ in port $p$. \\
\hline$C_{p l}^{j d}$ & $\begin{array}{l}\text { Capacity of containers incompatible with containers in } \mathcal{T}_{d} \\
\text { following separation principle } j \text { in location } l \text { in port } p .\end{array}$ \\
\hline$L_{r}^{\alpha t}$ & Total number of $\alpha \in\left\{20^{\prime}, 40^{\prime}\right\}$ containers of type $t$ in transport $r$. \\
\hline$R_{p l}^{D}$ & Number of TEU units to be discharged from location $l$ in port $p$. \\
\hline$R_{p l}^{O l V}$ & Number of over-stowing TEU units in location $l$ in port $p$. \\
\hline$R_{p l}^{A}$ & Number of TEU units to be loaded or discharged in location $l$ in port $p$. \\
\hline$W_{p l}^{T}$ & Maximum weight of all containers in location $l$ in port $p$ \\
\hline$W_{r}^{\alpha t}$ & Average weight of $\alpha \in\left\{20^{\prime}, 40^{\prime}\right\}$ containers of type $t$ in transport $r$. \\
\hline$G_{l}^{\{V, L, T\}}$ & Vertical $V$, longitudinal $L$ and transversal $T$ center of gravity of location $l$. \\
\hline$G_{p}^{M A X}\{V, L, T\}$ & $\begin{array}{l}\text { Maximum vertical } V \text {, longitudinal } L \\
\quad \text { and transversal } T \text { center of gravity in port } p .\end{array}$ \\
\hline$G_{p}^{M I N\{V, L, T\}}$ & $\begin{array}{l}\text { Minimum vertical } V \text {, longitudinal } L \\
\quad \text { and transversal } T \text { center of gravity in port } p \text {. }\end{array}$ \\
\hline$F_{p f}^{M A X}$ & Maximum stress force of frame $f$ in port $p$. \\
\hline$F_{p f}^{M I N}$ & Minimum stress force of frame $f$ in port $p$. \\
\hline$C^{O}$ & Cost of hatch over-stowage. \\
\hline$C^{R}$ & Cost of reduction of reefer container capacity. \\
\hline$C^{T}$ & Cost of crane makespan. \\
\hline$C^{\text {Time }}$ & Average crane time needed to load or unload a TEU unit. \\
\hline$M$ & Big number. \\
\hline$M_{3}$ & Sum of the TEU capacity of the locations in $\mathcal{L}_{h h^{\prime}}^{U}$ \\
\hline$M_{4}$ & Sum of the TEU capacity of the locations in $\mathcal{L}_{b}^{I N}$ \\
\hline$M_{h h^{\prime}}$ & Number of locations in $\mathcal{L}_{h h^{\prime}}^{U}$ \\
\hline$M_{b}$ & Number of locations in $\mathcal{L}_{b}^{I N}$ \\
\hline
\end{tabular}

Table 5: Variables

\begin{tabular}{|c|c|}
\hline$x_{r l}^{\alpha t}$ & Number of $\alpha=\left\{20^{\prime}, 40^{\prime}\right\}$ containers of type $t$ stowed in location $l$ during transport $r$. \\
\hline$\delta_{p l}$ & $\begin{array}{l}1 \text { if there are containers to load or discharge in port } p \text { below on-deck location } l \text {, } \\
0 \text { otherwise. }\end{array}$ \\
\hline$\phi_{p l}^{d}$ & $\begin{array}{l}1 \text { if there are containers containing dangerous goods of class } d \text { in location } l \\
\text { when the vessel leaves port } p, 0 \text { otherwise. }\end{array}$ \\
\hline$\lambda_{\left(h h^{\prime}\right) p}^{d}$ & $\begin{array}{l}1 \text { if there are containers incompatible with class } d \text { following segragation principle } 3 \\
\text { in under deck locations between two adjacent bulkheads } h \text { and } h^{\prime} \\
\text { when the vessel leaves port } p, 0 \text { otherwise. }\end{array}$ \\
\hline$\psi_{p b}^{d}$ & $\begin{array}{l}1 \text { if there are containers incompatible with class } d \text { following segragation principle } 4 \\
\text { in locations in pair } b \text { of inclusive adjacent bays when the vessel leaves port } p \text {, } \\
0 \text { otherwise. }\end{array}$ \\
\hline$y_{p l}^{O}$ & Number of hatch over-stowed TEU units to load or discharge in location $l$ in port $p$. \\
\hline$y_{p}^{T}$ & Crane makespan in port $p$ \\
\hline$y_{p l}^{R}$ & Reduction of reefer TEU capacity in location $l$ in port $p$. \\
\hline
\end{tabular}

$$
\begin{gathered}
\lambda_{\left(h h^{\prime}\right) p}^{d}+\frac{\sum_{l \in \mathcal{L}_{h h^{\prime}}^{U}} \phi_{p l}^{d}}{M_{\left(h h^{\prime}\right)}} \leq 1, \quad p \in \mathcal{P}, d \in \mathcal{D},\left(h h^{\prime}\right) \in \mathcal{H}^{\mathcal{A D} \mathcal{J}} \\
\sum_{r \in \mathcal{R}_{p}} \sum_{l \in \mathcal{L}_{b}^{I N}} \sum_{t \in \mathcal{T}_{d}^{4}} \sum_{\alpha \in\left\{20^{\prime}, 40^{\prime}\right\}} x_{r l}^{\alpha t} \leq \psi_{b p}^{d} M_{4}, \quad p \in \mathcal{P}, d \in \mathcal{D}, b \in \mathcal{B}^{I N} \\
\sum_{r \in \mathcal{R}_{p}} \sum_{l \in \mathcal{L}_{b}^{I N}} \sum_{t \in \mathcal{T}_{d}^{4}} \sum_{\alpha \in\left\{20^{\prime}, 40^{\prime}\right\}} x_{r l}^{\alpha t} \geq \psi_{b p}^{d}, \quad p \in \mathcal{P}, d \in \mathcal{D}, b \in \mathcal{B}^{I N} \\
\psi_{b p}^{d}+\frac{\sum_{l \in \mathcal{L}_{b}^{I N}} \phi_{p l}^{d}}{M_{b}} \leq 1, \quad p \in \mathcal{P}, d \in \mathcal{D}, b \in \mathcal{B}^{I N}
\end{gathered}
$$




$$
\begin{aligned}
& \sum_{r \in \mathcal{R}_{p}} \sum_{t \in \mathcal{T}} x_{r l}^{\alpha t} \leq C_{p l}^{\alpha}, \quad p \in \mathcal{P}, l \in \mathcal{L}, \alpha \in\left\{20^{\prime}, 40^{\prime}\right\} \\
& \sum_{l \in \mathcal{L}} x_{r l}^{\alpha t}=L_{r}^{\alpha t}, \quad t \in \mathcal{T}, r \in \mathcal{R}, \alpha \in\left\{20^{\prime}, 40^{\prime}\right\} \\
& \sum_{r \in \mathcal{R}_{p}} \sum_{t \in \mathcal{T}} \sum_{\alpha \in\left\{20^{\prime}, 40^{\prime}\right\}} W_{r}^{\alpha t} x_{r l}^{\alpha t} \leq W_{p l}^{T}, \quad p \in \mathcal{P}, l \in \mathcal{L} \\
& G_{p}^{M I N \rho} \leq \sum_{l \in \mathcal{L}} G_{l}^{\rho} \sum_{r \in \mathcal{R}_{p}} \sum_{t \in \mathcal{T}} \sum_{\alpha \in\left\{20^{\prime}, 40^{\prime}\right\}} W_{r}^{\alpha t} x_{r l}^{\alpha t} \leq G_{p}^{M A X \rho}, \quad p \in \mathcal{P}, \rho \in\{L, V, T\} \\
& F_{p f}^{M I N} \leq \sum_{l \in \mathcal{L}_{f}^{A F T}} \sum_{r \in \mathcal{R}_{p}} \sum_{t \in \mathcal{T}} \sum_{\alpha \in\left\{20^{\prime}, 40^{\prime}\right\}} W_{r}^{\alpha t} x_{r l}^{\alpha t} \leq F_{p f}^{M A X}, \quad p \in \mathcal{P}, f \in \mathcal{F} \\
& \sum_{l^{\prime} \in \mathcal{L}_{l}^{U}}\left(R_{p l^{\prime}}^{D}+\sum_{r \in \mathcal{R}_{p}^{A}} \sum_{t \in \mathcal{T}}\left(x_{r l^{\prime}}^{20 t}+x_{r l^{\prime}}^{40 t}\right)\right) \leq M \delta_{p l}, \quad p \in \mathcal{P}, l \in \mathcal{L}^{O} \\
& R_{p l}^{O V}+\sum_{r \in \mathcal{R}_{p}^{O V}} \sum_{t \in \mathcal{T}}\left(x_{r l}^{20 t}+2 x_{r l}^{40 t}\right)-M\left(1-\delta_{p l}\right) \leq y_{p l}^{O}, \quad p \in \mathcal{P}, l \in \mathcal{L}^{O} \\
& C^{\text {Time }} \sum_{r \in \mathcal{R}_{p}^{A}} \sum_{l \in \mathcal{L}_{b}^{E X}}\left(R_{p l}^{A}+\sum_{t \in \mathcal{T}}\left(x_{r l}^{20 t}+2 x_{r l}^{40 t}\right)\right) \leq y_{p}^{T}, \quad p \in \mathcal{P}, b \in \mathcal{B}^{E X} \\
& \sum_{r \in \mathcal{R}_{p}} \sum_{t \in \mathcal{T}} F_{p l}^{\tau}\left(x_{r l}^{20 t}+2 x_{r l}^{40 t}\right)-C_{p l}^{R} \leq y_{p l}^{R}, \quad p \in \mathcal{P}, l \in \mathcal{L} \\
& x_{r l}^{\alpha t} \in \mathbb{N} \cup\{0\}, \quad \alpha \in\left\{20^{\prime}, 40^{\prime}\right\}, t \in \mathcal{T}, r \in \mathcal{R}, l \in \mathcal{L} \\
& \delta_{p l}, \in\{0,1\}, \quad p \in \mathcal{P}, l \in \mathcal{L} \\
& \psi_{b p}^{d}, \in\{0,1\}, \quad p \in \mathcal{P}, b \in \mathcal{B}^{I N} d \in \mathcal{D} \\
& \phi_{p l}^{d}, \in\{0,1\}, \quad p \in \mathcal{P}, l \in \mathcal{L} d \in \mathcal{D} \\
& \lambda_{\left(h h^{\prime}\right) p}^{d}, \in\{0,1\}, \quad p \in \mathcal{P},\left(h h^{\prime}\right) \in \mathcal{H}^{A D J} d \in \mathcal{D} \\
& y_{p l}^{O}, \in \mathbb{N} \cup\{0\}, \quad p \in \mathcal{P}, l \in \mathcal{L} \\
& y_{p}^{T}, y_{p l}^{R} \geq 0, \quad p \in \mathcal{P}, l \in \mathcal{L}
\end{aligned}
$$

The objective function (1) minimizes the sum of costs of hatch over-stowage, stowage of non-reefer containers in reefer slots, and the crane makespan.

Constraints (2) and (3) ensure that TEU and reefer container capacities of each location in each port are respected. Constraints (4) and (5) set the binary variables $\phi_{p l}^{d}$ to 1 if there are containers with dangerous goods of class $d$ to load or already loaded in port $p$ in location $l$. Constraint (6) ensures that the number of incompatible containers following principles 2 and 3 in each location (for principle 3, only on-deck locations) never exceed the given limits.

Constraints (7) and (8) set the binary variables $\lambda_{\left(h h^{\prime}\right) p}^{d}$ to 1 if there are containers incompatible with containers containing dangerous goods of class $d$ following principle 3 to load or already loaded in port $p$ in the under deck locations between to adjacent bulkheads $h$ and $h^{\prime}$.

Constraint set 9 ensures that incompatible containers following principle 3 in below deck locations are separated by a bulkhead. 
Constraints 10 and 11 set the binary variables $\psi_{b p}^{d}$ to 1 if there are containers incompatible with containers containing dangerous goods of class $d$ following principle 4 to load or already loaded in port $p$ in locations the pair $b$ of inclusive adjacent bays.

Constraint set 12 ensures that incompatible IMO containers following principle 4 are separated by at least two even bays longitudinally, including a complete compartment. When incompatible IMO containers following principle 4 are stowed in below deck locations, additional bulkhead separation is needed, but there are always enough bulkheads with two even bays separation.

Constraint set 13 ensures that the number of containers of each length in each location is within the location's capacity, and the constraints in (14) ensure that all containers in all transports are loaded.

Constraint set (15) ensures that the weight of all containers in each location is within the weight limit of the location. The constraints in (16) ensure that the longitudinal, transversal and vertical centers of gravity are within the limits in each port visited by the container ship. Constraints (17) ensure that the downward force created by the cargo aft of each frame is within the limit. Since we assume constant displacement along the trip, we pre-compute the buoyancy forces and thus only restrict the weight distribution over the vessel accordingly.

Constraints $(18)-(21)$ compute values for the variables in the objective function. Constraint set (18) sets the binary variables $\delta_{p l}$ to 1 if there are containers to be handled in port $p$ in the location below a given on-deck location $l$. Constraint 19 then calculates the number of hatch over-stow containers in on-deck location $l$ in port $p$.

Crane makespan is the amount of time needed for the cranes to perform all loading and unloading operations, this is calculated by constraint set (20). In the Master Bay Planning, stacking rules are not taken explicitly into account. For this reason, some Slot Planning instances may be infeasible. A possible source of infeasibility is reefer containers, since they can only be stowed in slots with power plugs, which might be occupied by other container types. This is handled by reducing the capacity of reefer containers in a location by a proportional factor $F_{p l}^{\tau}$, where $F_{p l}^{\tau}=C_{p l}^{R} / C_{p l}^{T}$ for all non-reefer containers and a factor 1 for all reefer containers. Constraints (21) set the values for the variables $y_{p l}^{R}$, i.e., the reduction of the capacity of reefer containers within locations, which makes stowing non-reefer containers in reefer slots more costly.

Finally, constraints (22), 23), 24), 25), 26), 27) and (28) give domains for the variables.

\section{Computational Results}

We have tested our model on 19 instances. An overview of the instance characteristics can be found in Table 6. Neither industrial contacts nor other researchers have been able or willing to share instances with us, so we have generated random instances which we believe correspond closely to real world stowage problems. This means that the results in terms of objective function values are not very useful, as we have no other results to compare to. We are therefore in the following mainly focusing on solution times and the possibility to find optimal or near optimal solutions in reasonable time. Anyone who wants to use our test instances are welcome to do so, instances will be provided by the first author upon request.

A solution to the MP-MBPP gives the number of containers of each type for each transport to load in each location. A solution to the MP-MBPP will then serve as input data when a series of Slot Planning problems is solved in the next phase.

All experiments have been run on a Linux machine with Intel Core i7-5600U, CPU 2.60GHz $\times 4$ and 16 GB of memory. The model was implemented in Pyomo and solved with Gurobi 7.5.2.

Stowage planning problems, including the Multi-Port Master Bay Planning Problem, are NP hard, see 6] and [11] for proofs. For that reason, we did not expect to solve our model to optimality for real-world sized instances in reasonable time. To get an idea about solution times needed, we let Gurobi run for up to five hours first, and then for up to ten minutes, for each instance. The results are given in Tables 7 and 8 , respectively. Within five hours, 11 instances are solved to optimality with the default Gurobi optimality gap of $0.01 \%$. The remaining eight instances are not solved to optimality within the given run time, but all of them reach an optimality gap of less than $0.1 \%$. Within ten minutes, nine instances are solved to optimality with the default Gurobi optimality gap. The remaining ten instances are not solved to optimality within the given run time, but all of them reach an optimality gap of less than $0.5 \%$. Hatch over-stowage occur in one instance with a maximum of one TEU container, see Table 8. Note that we have not made any relaxations of the integer and binary variables. 
Table 6: Overview of instances: Columns under Vessel present ship dependent data: Loc is the total number of locations and Cap is the capacity of the ship in TEU. Columns under Route give information about the route, Port indicates the number of ports along the route, Current load and Forecast load $\left(20^{\prime}\right.$ and $\left.40^{\prime}\right)$ are the total number of containers to be loaded in current and downstream ports. Type indicates the number of different types of containers $(6=$ standard, reefer, four different IMO classes, $5=$ standard, reefer, three different IMO classes, 4 = standard, reefer, two different IMO classes, $3=$ standard, reefer, one IMO class, $2=$ standard, reefer and $1=$ standard). Principle lists the separation principles for the IMO containers in the given instance. Transports is the total number of active transports, and the two last columns show the number of integer and binary variables in the model after preprocessing.

\begin{tabular}{|c|c|c|c|c|c|c|c|c|c|c|c|c|}
\hline \multirow{3}{*}{ ID } & \multicolumn{2}{|c|}{ Vessel } & \multicolumn{5}{|c|}{ Route } & \multirow{3}{*}{ Type } & \multirow{3}{*}{ Principle } & \multirow{3}{*}{ Transport } & \multicolumn{2}{|c|}{ Number of Variables } \\
\hline & \multirow[t]{2}{*}{ Loc } & \multirow[t]{2}{*}{ Cap } & \multirow[t]{2}{*}{ Port } & \multicolumn{2}{|c|}{ Current load } & \multicolumn{2}{|c|}{ Forecast load } & & & & & \\
\hline & & & & $20^{\prime}$ & $40^{\prime}$ & $20^{\prime}$ & $40^{\prime}$ & & & & Integer & Binary \\
\hline 1 & 66 & 2376 & 6 & 718 & 498 & 932 & 893 & 6 & $2,3,4$ & 15 & 25618 & 1858 \\
\hline 2 & 120 & 3600 & 6 & 961 & 813 & 1632 & 1443 & 6 & 2,4 & 15 & 46580 & 3380 \\
\hline 3 & 234 & 7020 & 6 & 1084 & 2003 & 1900 & 3422 & 6 & $2,3,4$ & 15 & 90802 & 6562 \\
\hline 4 & 234 & 7020 & 6 & 1234 & 2063 & 2000 & 3524 & 6 & 2 & 15 & 90802 & 6562 \\
\hline 5 & 234 & 7020 & 6 & 1084 & 2003 & 1900 & 3422 & 1 & - & 15 & 14742 & 702 \\
\hline 6 & 234 & 7020 & 6 & 1084 & 2003 & 1900 & 3422 & 2 & - & 15 & 28782 & 702 \\
\hline 7 & 234 & 7020 & 6 & 1384 & 2123 & 2100 & 3626 & 6 & 2 & 15 & 90802 & 6562 \\
\hline 8 & 300 & 9000 & 6 & 1668 & 2378 & 1935 & 3407 & 6 & $2,3,4$ & 15 & 116420 & 8420 \\
\hline 9 & 300 & 9000 & 6 & 1668 & 2378 & 1935 & 3407 & 5 & $2,3,4$ & 15 & 96540 & 6540 \\
\hline 10 & 300 & 9000 & 6 & 1668 & 2378 & 1935 & 3407 & 4 & 2,4 & 15 & 76660 & 4660 \\
\hline 11 & 300 & 9000 & 6 & 1668 & 2378 & 1935 & 3407 & 2 & - & 15 & 36900 & 900 \\
\hline 12 & 300 & 9000 & 6 & 1668 & 2378 & 1935 & 3407 & 1 & - & 15 & 18900 & 900 \\
\hline 13 & 276 & 18032 & 6 & 3040 & 3542 & 2900 & 4425 & 6 & $2,3,4$ & 15 & 107088 & 7728 \\
\hline 14 & 276 & 18032 & 6 & 2540 & 3142 & 2900 & 4425 & 5 & $2,3,4$ & 15 & 88818 & 6018 \\
\hline 15 & 276 & 18032 & 6 & 2540 & 3142 & 2900 & 4425 & 4 & 2,4 & 15 & 70528 & 4288 \\
\hline 16 & 276 & 18032 & 6 & 2540 & 3142 & 2900 & 4425 & 3 & - & 15 & 52238 & 2558 \\
\hline 17 & 276 & 18032 & 6 & 2540 & 3142 & 2900 & 4425 & 2 & - & 15 & 33948 & 828 \\
\hline 18 & 276 & 18032 & 6 & 2540 & 3142 & 2900 & 4425 & 1 & - & 15 & 17388 & 828 \\
\hline 19 & 276 & 18032 & 6 & 2540 & 3142 & 2900 & 4425 & 6 & $2,3,4$ & 15 & 107108 & 7748 \\
\hline
\end{tabular}

Table 7: MP-MBPP results with 5 hours run time. The first column is the instance number, the second column is the best found objective value. The third column is the number of hatch over-stowages in the route. The fourth column is the run time used by the solver to find the best solution, and the last column is the optimality gap, where 0 means that the default Gurobi optimality gap of $0.01 \%$ or less was reached.

\begin{tabular}{ccccc}
\hline ID & Obj & HOS(TEU) & Run time(in seconds) & Gap $(\%)$ \\
\hline 1 & 15199 & 0 & 3327 & 0 \\
2 & 14510 & 0 & 45 & 0.06 \\
3 & 13880 & 0 & 570 & 0 \\
4 & 14160 & 0 & 8160 & 0.04 \\
5 & 13860 & 0 & 17 & 0 \\
6 & 13840 & 0 & 35 & 0 \\
7 & 15230 & 0 & 1500 & 0.06 \\
8 & 12950 & 0 & 800 & 0 \\
9 & 12536 & 0 & 1878 & 0.03 \\
10 & 12300 & 0 & 260 & 0.08 \\
11 & 12070 & 0 & 65 & 0 \\
12 & 12070 & 0 & 32 & 0 \\
13 & 19450 & 0 & 527 & 0.04 \\
14 & 18120 & 0 & 520 & 0.05 \\
15 & 16580 & 0 & 350 & 0 \\
16 & 16580 & 0 & 245 & 0 \\
17 & 16730 & 0 & 25 & 0 \\
18 & 16720 & 0 & 25 & 0 \\
19 & 18360 & 0 & 729 & 0.03 \\
\hline
\end{tabular}

The results in Table 7 show that optimal or close to optimal solutions can be found in five hours for all instances included in our experiments, we think this is due to both the fact that modern solvers are very efficient, and that the extensions we have made to the MP-MBPP model have not made it significantly harder to solve. 
Table 8: MP-MBPP results with 10 minutes run time. The column headers are the same as in Table 7

\begin{tabular}{ccccc}
\hline ID & Obj & HOS(TEU) & Run time(in seconds) & Gap (\%) \\
\hline 1 & 15200 & 0 & 560 & 0.03 \\
2 & 14510 & 0 & 45 & 0.057 \\
3 & 13880 & 0 & 250 & 0 \\
4 & 14170 & 0 & 300 & 0.12 \\
5 & 13860 & 0 & 16 & 0 \\
6 & 13840 & 0 & 35 & 0 \\
7 & 15290 & 1 & 130 & 0.45 \\
8 & 12980 & 0 & 590 & 0.23 \\
9 & 12540 & 0 & 400 & 0.04 \\
10 & 12300 & 0 & 90 & 0.08 \\
11 & 12070 & 0 & 65 & 0 \\
12 & 12070 & 0 & 30 & 0 \\
13 & 19450 & 0 & 490 & 0.04 \\
14 & 18120 & 0 & 270 & 0.05 \\
15 & 16580 & 0 & 240 & 0 \\
16 & 16580 & 0 & 70 & 0 \\
17 & 16730 & 0 & 25 & 0 \\
18 & 16720 & 0 & 20 & 0 \\
19 & 18360 & 0 & 310 & 0.03 \\
\hline
\end{tabular}

Five hours is too long time in a practical setting, so we have run the instances with larger optimality gaps to see how long time is needed to find a solution within the given gap, and how good this solution is compared to the "true" optimal solution. The results of these runs are given in Table 9.

Table 9: MP-MBPP results with different optimality gaps. For each gap, the table shows the number of hatch over-stowages (HOS) in the entire route, the optimality gap and the run time. A 0 in the Gap column means that the default Gurobi optimality gap of $0.01 \%$ was reached.

\begin{tabular}{|l|ccc|ccc|ccc|}
\hline & \multicolumn{3}{|c|}{$1 \%$ Gap } & \multicolumn{3}{c|}{$0.5 \%$ Gap } & \multicolumn{3}{c|}{$0.1 \%$ Gap } \\
ID & HOS & Gap $(\%)$ & Time(sec) & HOS & Gap(\%) & Time(sec) & HOS & Gap $\%$ (imesec) \\
\hline 1 & 0 & 0.82 & 20 & 0 & 0.34 & 100 & 0 & 0.06 & 110 \\
2 & 0 & 0.06 & 45 & 0 & 0.06 & 45 & 0 & 0.06 & 45 \\
3 & 0 & 0.27 & 90 & 0 & 0.27 & 90 & 0 & 0.05 & 260 \\
4 & 0 & 0.12 & 320 & 0 & 0.12 & 320 & 0 & 0.05 & 751 \\
5 & 1 & 0.57 & 10 & 0 & 0.43 & 11 & 0 & 0.07 & 13 \\
6 & 0 & 0.82 & 34 & 0 & 0.02 & 35 & 0 & 0.02 & 34 \\
7 & 1 & 0.52 & 120 & 1 & 0.45 & 130 & 0 & 0.06 & 1500 \\
8 & 1 & 0.69 & 370 & 0 & 0.23 & 590 & 0 & 0 & 800 \\
9 & 0 & 0.28 & 240 & 0 & 0.28 & 240 & 0 & 0.04 & 340 \\
10 & 0 & 0.08 & 72 & 0 & 0.08 & 72 & 0 & 0.08 & 72 \\
11 & 0 & 0.25 & 15 & 0 & 0.25 & 15 & 0 & 0 & 65 \\
12 & 0 & 0.41 & 20 & 0 & 0.41 & 20 & 0 & 0.0 & 32 \\
13 & 0 & 0.04 & 520 & 0 & 0.04 & 520 & 0 & 0.04 & 520 \\
14 & 1 & 0.11 & 190 & 1 & 0.11 & 190 & 0 & 0.05 & 270 \\
15 & 0 & 0.37 & 135 & 0 & 0.37 & 135 & 0 & 0.02 & 190 \\
16 & 0 & 0.02 & 60 & 0 & 0.02 & 60 & 0 & 0.02 & 60 \\
17 & 2 & 0.45 & 10 & 2 & 0.45 & 10 & 0 & 0.02 & 25 \\
18 & 0 & 0.17 & 5 & 0 & 0.17 & 5 & 0 & 0.02 & 8 \\
19 & 0 & 0.13 & 170 & 0 & 0.13 & 170 & 0 & 0.03 & 330 \\
\hline \hline
\end{tabular}

As expected, run times decrease with increasing optimality gaps. With an optimality gap of $1 \%$ or $0.5 \%$, most instances are solved within ten minutes. With $0.1 \%$ optimality gap, sixteen instances are solved in less than ten minutes. The run time is different from instance to instance, that is, the run time also seem to be affected by the number of different containers types.

The results show that by increasing optimality gaps, the solution times can be brought down to quite acceptable levels without giving away much in terms of solution quality. We see that the "true" optimal solution, the one found with Gurobi's default gap, is often found also with an increased gap. Which gap to use and which amount of time to be regarded as "reasonable time" will depend on the situation, this has to be decided by the problem owner who is going to use the solution for planning.

In general, the results from all our experiments reveal a difference between "easy" and "hard" instances, instances without IMO containers are solved faster than instances where IMO containers are included. Instances 
$5,6,11,12,16,17$ and 18 have the shortest run times in all experiments, the only exception is instance 2 , which is quite small in terms of container capacity and number of locations. This indicates that the inclusion of IMO containers, which is necessary to handle real-world problems, adds some complexity and run time, but the problems are still solvable in reasonable time.

\section{Conclusions}

In this paper, we have extended the Multi-Port Master Bay Planning Problem by including IMO containers holding dangerous goods. This extension brings our model closer to the real-world problem which actually needs to be solved in practice. Computational experiments show that our model can be solved to optimality or near optimality in reasonable time using a standard MIP solver.

We are currently looking into Slot Planning where the same extensions are taken into account, we see this as a natural extension of the work presented here. In the Slot Planning Problem containers are assigned to specific positions in each location. This problem also changes when IMO containers following separation principles 2 and 3 are considered, as the actual position of an IMO container in a bay will define possible locations for other incompatible IMO containers following separation principles 2 and 3 in adjacent bays.

\section{References}

[1] Ambrosino, D., Sciomachen, A.: Using a Bin Packing Approach for Stowing Hazardous Containers into Containerships. In: Fasano, G., Pintér, J. (eds): Optimized Packings with Applications. Springer Optimization and Its Applications, vol 105, pp. 1-17 (2015)

[2] Ambrosino, D., Sciomachen, A., Tanfani, E.: Stowing a containership: the master bay plan problem. Transportation Research Part A, 38(2), 81-99 (2004)

[3] Ambrosino, D., Anghinolfi, D., Paolucci, M., Sciomachen, A.: Modelling the multi-port master bay problem. In: Dauer, R.R.M., Sagarra, R.M., de Osés, F.X.M (Eds.): Maritime Transport IV. UPC (Universititat Politecnica de Catalunya), Barcelona, pp. 63-73 (2009)

[4] Ambrosino, D., Paolucci, M., Sciomachen, A.: Experimental evaluation of mixed integer programming models for the multi-port master bay plan problem. Flex Serv Manuf 27, 263-284 (2015)

[5] Ambrosino, D., Paolucci, M., Sciomachen, A. Computational evaluation of a MIP model for multi-port stowage planning problems. Soft Computing 21(7), 1753-1763 (2017)

[6] Avriel, M., Penn, M., Shpirer, N.: Container ship stowage problem: complexity and connection to the colouring of circle graphs. Discrete Applied Mathematics 103(1-5), 271-279 (2000)

[7] Christiansen, M., Fagerholt, K., Ronen, D.: Ship Routing and Scheduling: Status and Perspectives. Transportation Science, 38 (1), 1-18 (2004)

[8] Fan, L., Low, M.Y.H., Ying, H.S., Jing, H.W., Min, Z., Aye, W.C.: Stowage planning of large containership with tradeoff between crane workload balance and ship stability. In Proceedings of the International MultiConference of Engineers and Computers Scientists 3, 1-7 (2010)

[9] Kang, J.-G., Kim, Y.-D.: Stowage planning in maritime container transportation. Journal of the Operational Research Society 53(4), 415-426 (2002)

[10] Li, F., Tian, C., Cao, R., Ding, W.: An Integer linear programming for container stowage problem. In International Conference on Computational Science - ICCS 2008, 853-862 (2008)

[11] Pacino, D., Delgado, A., Jensen, R.M., Bebbington, T.: Fast generation of near-optimal plans for ecoefficient stowage of large container vessels. In Proceedings from International Joint Conference on Artificial Intelligence - ICCL'11, 286-301 (2011)

[12] Pacino, D., Delgado, A., Jensen, R.M., Bebbington, T.: An accurate model for seaworthy container vessel stowage planning with ballast tanks. In Proceedings from International Conference on Computational Logistics - ICCL 2012, 17-32 (2012)

[13] Parreño, F., Pacino, D., Alvarez-Valdes, R.: A GRASP algorithm for the container stowage Slot Planning problem, Transportation Research Part E 94, 141-157 (2016)

[14] Wei-Ying, Z., Yan, L., Zhuo-Shang, J.: Model and algorithm for container ship stowage planning based on bin-packing problem. Journal of Marine Science and application, 4(3), 30-36 (2005)

[15] Wikipedia. https://en.wikipedia.org/wiki/List_of_largest_container_ships. [Online; accessed September 29, 2017]

[16] Wilson, I.D., Roach, P.A.: Container stowage planning: a methodology for generating computerised solutions. Journal of the Operational Research Society 51(11), 1248-1255 (2000)

[17] Wilson, D., Roach, P.A., Ware J.A.: Container stowage pre-planning: using search to generate solutions, a case study. Knowledge-Based Systems 14(3-4), 137-145 (2001)

[18] Lawrence, S.A.: International sea transport: the years ahead. Lexington Books (1972)

[19] IMO IMDG.1: International Maritime Dangerous Goods Code Vol. 1, International Maritime Organization (2006) 